\title{
Erratum to: Perioperative levetiracetam for prevention of seizures in supratentorial brain tumor surgery
}

Iris Zachenhofer • Markus Donat •

Stefan Oberndorfer - Karl Roessler

Published online: 23 July 2010

(C) Springer Science+Business Media, LLC. 2010

Erratum to: J Neurooncol

DOI 10.1007/s11060-010-0235-4

There was an error in the Abstract of the original publication. The wrong seizure frequency (2.5) was specified in the penultimate sentence of the Abstract. It should have read 2.6, as specified elsewhere in the Abstract and Results sections.

The online version of the original article can be found under doi:10.1007/s11060-010-0235-4.

I. Zachenhofer $(\bowtie) \cdot$ M. Donat $\cdot$ K. Roessler Department of Neurosurgery, Academic Teaching Hospital Feldkirch, Carinagasse 47, 6807 Feldkirch, Austria

e-mail: iris.zachenhofer@lkhf.at

S. Oberndorfer

Department of Neurology and LBI for Neurooncology, Kaiser

Franz Josef Hospital, SMZ-Süd, Vienna, Austria 